\title{
Regional Chemotherapy and Brachytherapy for Malignant Glioma - Clinical Experience and a Serial Experiments
}

\author{
Li Anmin, Fu Xiangping, Zhao Ming, Zhang Zhiwen, \\ Yi Linhua, Xue Jinghui and Zhang Yipeng \\ Department of Neurosurgery, First Affiliated Hospital of Chinese PLA General Hospital,
}

China

\section{Introduction}

Malignant glioma (MG) is the most common type of malignant tumors derived from neuroepithelial tissue, and accounts for $46 \%$ of brain tumors. It has an incidence of 30 $100 /$ million and ranks third in adult mortality and second in child mortality in all cancer patients. Compared with malignant tumors from other tissues and organs, MG has much lower treatment success rates. Despite global efforts over the past thirty years, there has been no major breakthrough in treatment and patient survival has not significantly improved. The median survival time after diagnosis is eight months in patients receiving surgery alone and 11 months in patients receiving surgery plus adjuvant radiotherapy/chemotherapy. Conventional treatments for MG include surgical resection, adjuvant whole brain radiotherapy (WBRT), and systemic chemotherapy. Limitations of these treatments include:

1. Surgical resection: $\mathrm{MG}$ is highly invasive. As a result, total resection is typically not achieved in surgery. The operation may also activate residual tumor cells from the G0 phase to the proliferation phase, resulting in tumor recurrence of malignancy.

2. Post-operative WBRT. The effective dose for MG (73-80 Gy) is higher than the maximum tolerated dose for brain tissue $(60 \mathrm{~Gy})$. The therapeutic effects at a dose of 60 Gy are mediated primarily by radioactive ions that stimulate endotheliocytosis in the microvascular bed of the tumor. The endotheliocytosis results in embolism and decreased blood supply to tumor.

3. Post-operative chemotherapy. Upon systemic treatment, only $\sim 20 \%$ of chemotherapeutic agents reach the brain. The blood brain barrier (BBB) around the post-operative tumor cavity also prevents the chemotherapeutic agents from reaching the site of action.

The weak immunogenicity of the glioma membrane and the heterogeneity of the cells have limited the application of immunotherapy. The unique biological properties and lack of effective clinical treatment creates a challenge for clinical practice and basic experimental research $[1,2]$. 
The growth of MG tends to be localized. Such a feature may represent an opportunity to develop novel treatment for MG [3]. Specifically, we propose that localized tumor should be treated with regional therapy.

Over 18 years of clinical research (Apr 1991 to Dec 2008), the authors developed new regional treatments. These new treatments incorporated three therapeutic concepts: emphasizing the "first strike" to the tumor, maintaining a high quality of life for the patients, and devising individual treatment plans for patients.

Clinical research provided satisfactory and promising outcomes for regional therapy. In addition, in vivo and in vitro experimental results showed that the implementation of regional treatment methods could control residual tumor growth and invasive behaviors. Data accumulated with 10-year follow-up in 379 patients confirmed that the new regional treatments improved the survival as well as the quality of life in patients with MG.

\section{New regional therapies for $M G$}

The authors introduced the idea that localized tumors should be treated with regional therapy and developed seven new methods for such regional therapy. With these new methods, we achieved 16.6\% 3-year survival rate in MG patients. Strikingly, the tumor disappeared in $6.3 \%$ of the cases. The seven new methods can be classified as regional chemotherapy or brachytherapy.

i. Regional chemotherapy

1. Intra-tumoral interstitial chemotherapy

2. Selective/super-selective interventional chemotherapy via the cerebral artery

3. High-dose chemotherapy supported by autologous stem cells

ii. Brachytherapy

1. Intra-tumoral brachytherapy

2. Immunologically targeted radiotherapy via ${ }^{131}$ I labeled $\mathrm{McAb}$

3. Tumor interstitial brachytherapy

4. Brachytherapy for MG located in the brain stem or spinal cord

\section{Intra-tumoral interstitial chemotherapy}

Regional chemotherapy was explored for decades in the world [4-7]. In 1991, the authors used a patented chemotherapy reservoir (Li Anmin I reservoir, Fig.1-A) for postoperative intratumor interstitial chemotherapy. From Jan 2001 to Dec 2008, 151 of 379 patients received this chemotherapy.

\subsection{Methods}

After MG resection, the chemotherapy reservoir was implanted into the residual tumor cavity (Fig.1-B). Chemotherapeutic agents were injected into the extracranial capsule and then into the residual tumor cavity via the reservoir tube. The chemotherapeutic agents used for this treatment (BCNU, VM, and ACNU) have low molecular weight, and could permeate the residual tumor cavity wall and tumor cell membrane. Doses for these agents were $25 \mathrm{mg}$ for BCNU, $50 \mathrm{mg}$ for VM26, and 25-50 mg for ACNU. The injection began at 7 $\mathrm{d}$ after the operation and continued daily for $4 \mathrm{~d}$. When tumor growth was under control (Fig. 2), the interval between the injections was increased to $30-40 \mathrm{~d}$. The entire treatment lasted for $2 \mathrm{yr}$. 


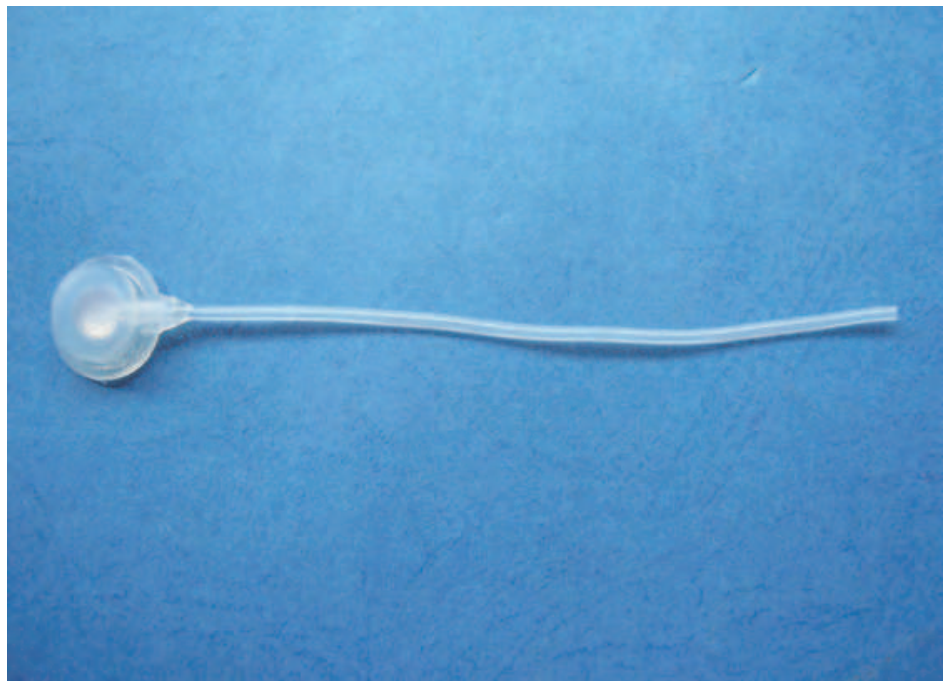

Fig. 1-A. Photo of Chemotherapeutic Reservoir （Li Anmin Type I Reservoir）

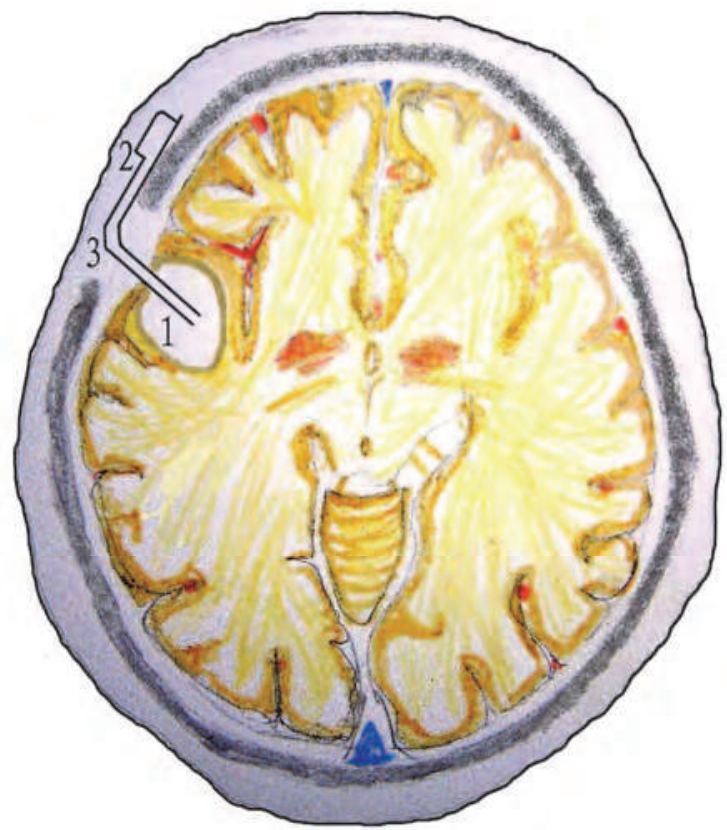

Fig. 1-B. The sketch of interstitially intratumoral chemotherapy postoperatively: 1. Residual tumor cavity, 2. Valve of the reservoir, 3. Tube of the reservoir 


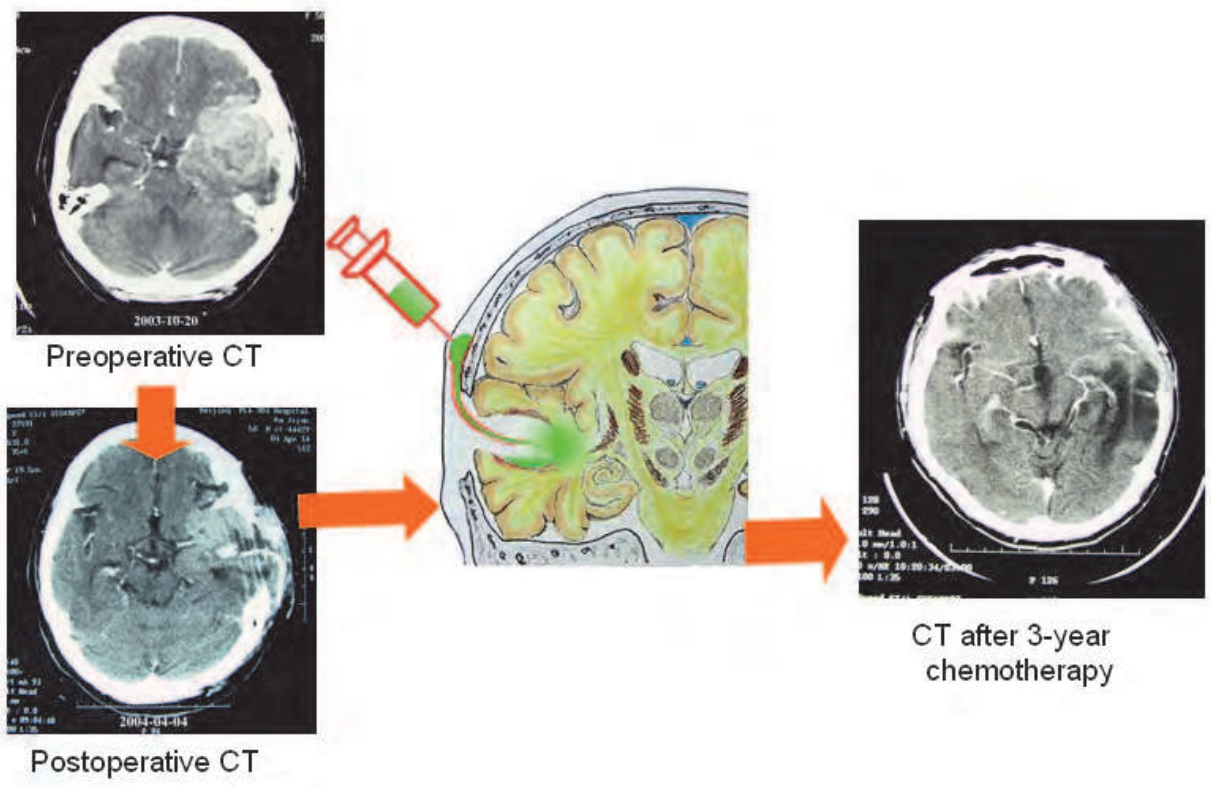

Fig. 2. The sketch of interstitially intratumoral chemotherapy

\subsection{Side effects}

There was no general toxicity during or after drug injection. Headache (typically tolerable was observed in some patients receiving VM26 or BCNU. Seizure developed in $2.7 \%$ of the patients receiving VM26 or BCNU. ACNU did not cause discomfort in any patient (Table 1).

The Li Anmin I reservoir has several advantages over Ommaya reservoir. First, the extracranial capsule of the new reservoir has a steel or titanium basement plate, which prevents it from being pierced during the drug injection. Second, the tube of the new reservoir extends from the side of the external capsule rather than from the bottom as in the Ommaya reservoir[8,9]. This new configuration facilitates fixation and reduces the capsule volume.

Overall, hawse has achieved positive therapeutic outcomes with tolerable adverse effects with this method. As a result, it is now widely adopted in China.

\begin{tabular}{llll}
\hline & BCNU & VM26 & ACNU \\
\hline Inhibitive efficiency & ++ & + & +++ \\
Effective radius & $\mathrm{cm}$ & $>3 \mathrm{~cm}$ & $<3 \mathrm{~cm}$ \\
Necrosis feature & Coagulation & Liquefaction & Coagulation \\
Local effect & necrosis & necrosis & necrosis \\
Toxicity & ++ & +++ & ++ \\
\hline
\end{tabular}

Table 1. Three chemotherapeutic agents used in intra-tumoral interstitial chemotherapy. 


\section{Selective/super-selective interventional chemotherapy via the cerebral artery}

In early 1990s in China, interventional therapy via the cerebral artery was primarily a tool for the diagnosis and treatment of cerebrovascular diseases. In 1993, the authors presented the first use of interventional chemotherapy via cerebral artery for the treatment of MG.0

\subsection{Methods}

There are three major methods currently used by the authors in the cerebral interventional chemotherapy (Fig. 3): intervention by common carotid artery, intervention by femoral-internal carotid (supraclinoid)/vertebrobasilar artery (selective chemotherapy), and intervention by femoral-tumor feeding artery (super-selective chemotherapy).

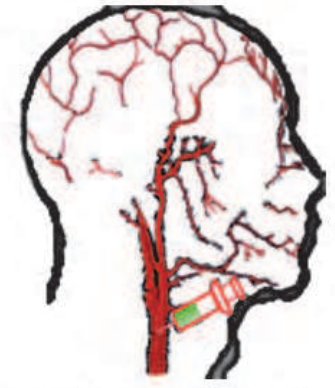

Chemotherapeutic agent administered via carotid artery puncture

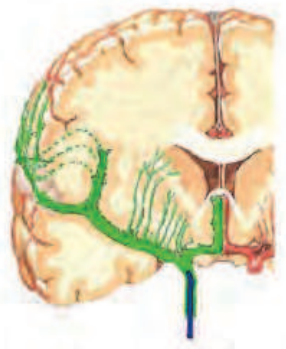

Selective interventional chemotherapy

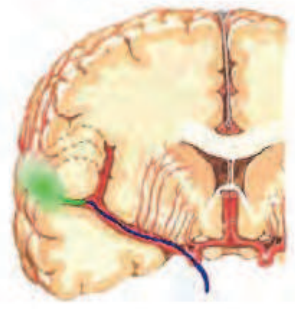

Superselective interventional chemotherapy

Fig. 3. The sketch of interventional chemotherapy via cerebral artery

\subsection{Side effects}

From Apr 1991 to Dec 2008, 677 patients received this therapy, and 4916 operations were performed. The side effects for interventional chemotherapy included three cases of vision reduction, perhaps due to embolism of retinal arteriole by chemotherapeutic microlipoparticles, one case of hemiplegia caused by breaking off of the plaque in the bifurcation and embolized of ICA during the punctuation of CCA. Leucopenia and thrombocytopenia developed in 92 cases $(24.4 \%)$, but recovered within four weeks of withdrawal in most cases. In seven cases, white blood cell count was too low to continue the chemotherapy. Spontaneous hemorrhagic tendency (the thrombocytopenia after chemotherapy had no effective treatment to promote the recovery of bone marrow function) occurred in two cases. Myelofibrosis was observed in one case.

Cerebral artery interventional chemotherapy significantly reduced the adverse effects of chemotherapeutic agents and elevated the intratumoral local drug concentration by more than 15-fold (Fig. 4). From 2001 to 2008, 283 of 379 cases were treated with interventional chemotherapy, and 158 cases $(56.0 \%)$ had favorable outcomes. This method has been adopted widely (Fig. 5). 
Typical case:

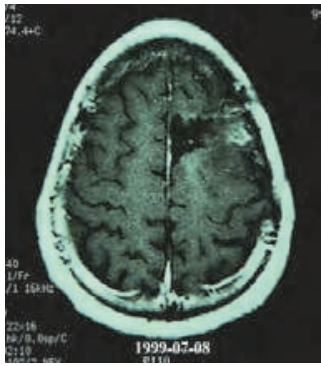

MRI after first surgery

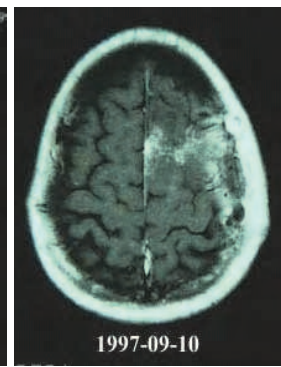

MRI after second surgery

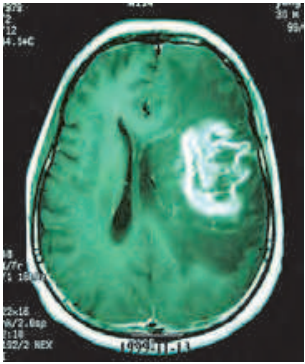

MRI of glioma recurrence

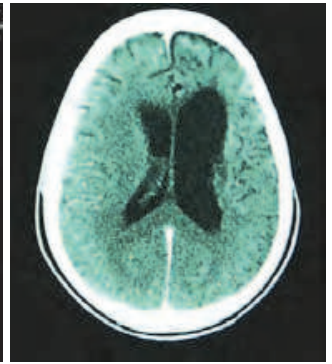

CT after 8-month chemotherapy

Fig. 5. The male patient was 30 years old with recurrent glioblastoma multiform, treated with interventional chemotherapy

\section{High dose chemotherapy supported by Autologous Peripheral Blood Bone Marrow Stem Cell (APBBMSC)}

Based on the dose-effect curve of chemotherapeutic agents, the authors used high-dose chemotherapy (twice the normal dose) to treat MG. In 2003, we introduced APBBMSCsupported high-dose chemotherapy for MG. Beginning at five days before chemotherapy, $300 \mu \mathrm{g}$ of granulocyte colony stimulating factor (G-CSF) was injected daily to stimulate APBBMSCs. The APBBMSCs were isolated from peripheral blood and concentrated in a 60 $\mathrm{mL}$ suspension. The cell concentration was adjusted to $1.0 \times 10^{9}$ cells $/ \mathrm{mL}$ with Tc-199 cell culture solution blended with buffer solution (60\% Tc-199, 20\% dimethyl sulfoxide, $20 \%$ autologous plasma). APBBMSC was stored in liquid nitrogen. After the high-dose chemotherapy, frozen APBBMSCs were thawed rapidly at $4^{\circ} \mathrm{C}$ and administered intravenously at 48-72 $\mathrm{h}$ post-chemotherapy (Fig. 6).

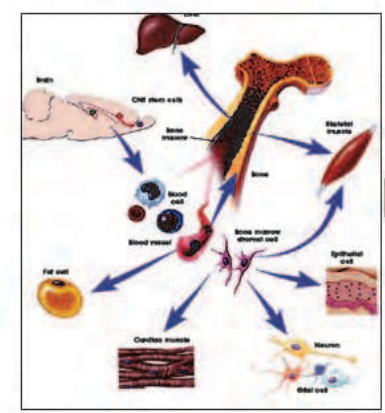

To activate bone marrow hemopoietic stem cells into peripheral circulation

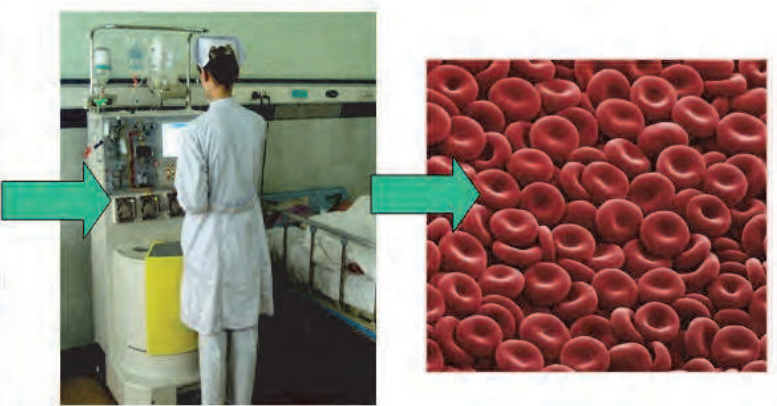

The hemopoietic stem cells were collected and condensed.
The bone marrow stem cells were infused intravenously.

Fig. 6 . The procedure of chemotherapy supported by autotransplantation of peripheral blood bone marrow stem cells. 
Following this treatment, the WBC count decreased for 3-7 d, reaching the lowest values at 5-10 d, and increased to $>1.0 \times 10^{9}$ cells $/ \mathrm{L}$ in 6-10 d. The PLT levels typically returned to $>50.0 \times 10^{9} / \mathrm{L}$ in $12-15 \mathrm{~d}$. In the 74 patients receiving only conventional chemotherapy, WBC count reduced to $<1.0 \times 10^{9} / \mathrm{L}$ and PLT levels reduced to $<20.0 \times 10^{9} / \mathrm{L}$. The low levels remained for 16-31 days before returning to normal.

In this series, the overall effective rate was $55.6 \%$ (total number of patients: $27 ; 2$ CR cases, 13 PR cases, 10 MR cases, 1 NC case, and 1 PD case; Fig. 7).

Typical case:

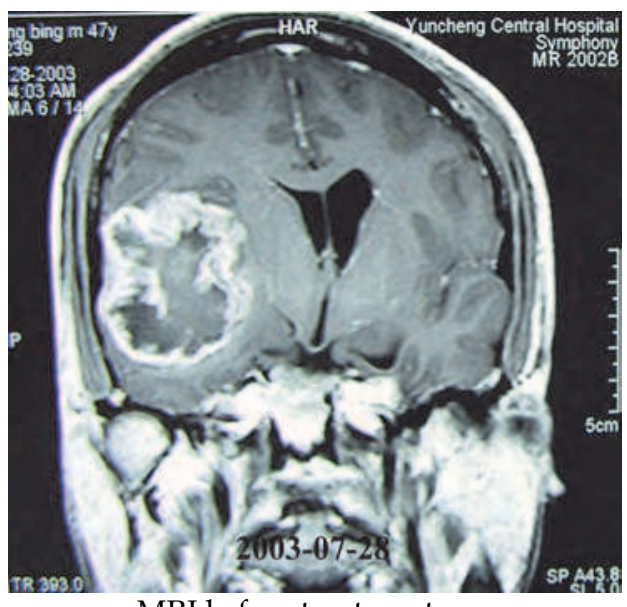

MRI before treatment

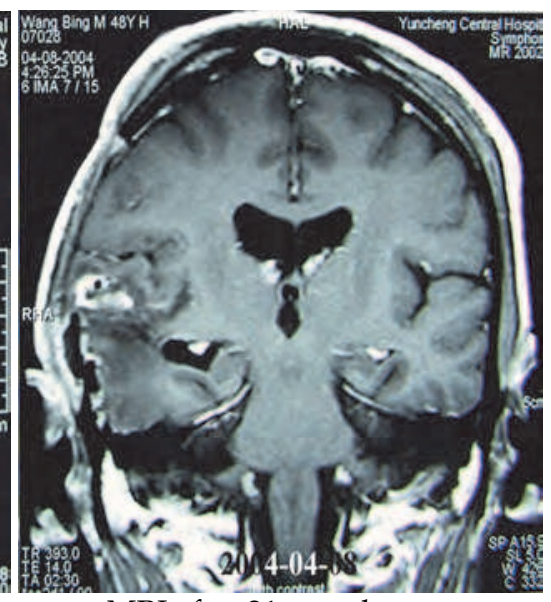

MRI after 21-month treatment

Fig. 7. The male patient was 49 years old with recurrent GBM, treated with chemotherapy supported by autotransplantation of peripheral blood bone marrow stem cells, superselectively intervetional chemotherapy and targeted immunoradiotherapy with monoclonal antibody labelled ${ }^{131}$ I.

This study indicated that APBBMSC-supported high-dose chemotherapy offers the advantage of rapid recovery of bone marrow after high-dose chemotherapy. Compared with bone marrow transplants following chemotherapy, APBBMSC-supported high-dose chemotherapy is easy to perform and could achieve rapid recovery of hematopoietic function with limited side effects [10].

\section{Intra-tumoral brachytherapy}

In 1993, the authors developed a radiotherapy reservoir (Li Anmin II reservoir, Fig. 8-A) to perform postoperative intra-tumoral brachytherapy for MG. This treatment was used in 172 of the 379 patients.

\subsection{Methods}

After surgical removal of the tumor, a brachytherapy reservoir was implanted into the residual tumor cavity, and the valve of the reservoir was embedded subcutaneously (Fig. 8B). Radioactive isotopes (125I or ${ }^{131} \mathrm{I}$ ) were injected through the reservoir valve into the 
reservoir. The reservoir formed an oval-shaped radioactive envelope (Fig. 9), and produced localized, long-term, high-dosage irradiation to the residual cavity and the surrounding region for two half lives (125I $t_{1 / 2}=120$ days and ${ }^{131} \mathrm{I} \mathrm{t}_{1 / 2}=16$ days).

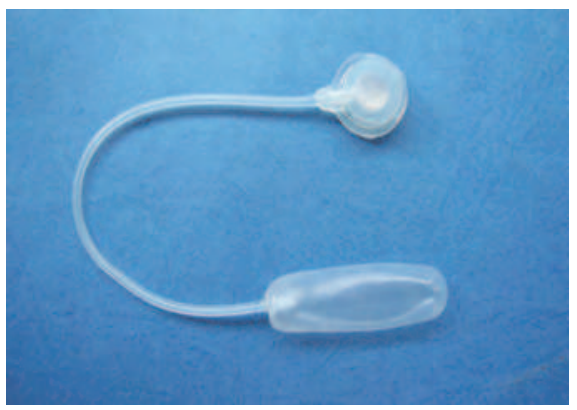

Fig. 8-A. Photo of Radiotherapeutic Reservoir (LiAnmin Type II reservoir)

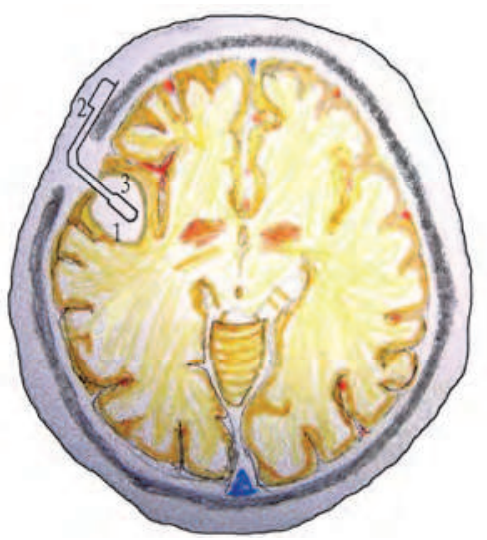

Fig. 8-B. The sketch of intratumoral brachytherapy: 1.Residual tumor cavity, 2. Valve of the reservoir, 3. Sack of the reservoir

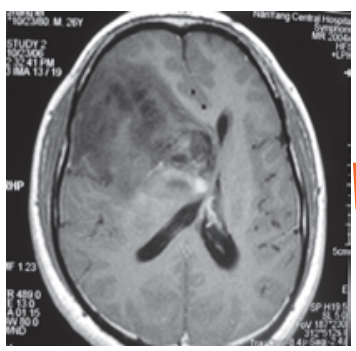

MRI before treatment

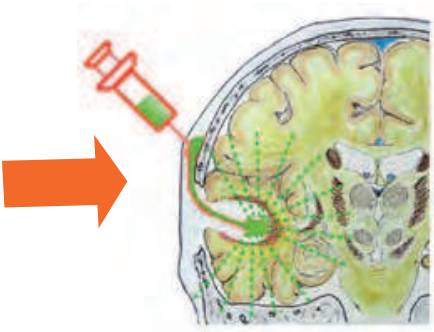

The sketch of treatment

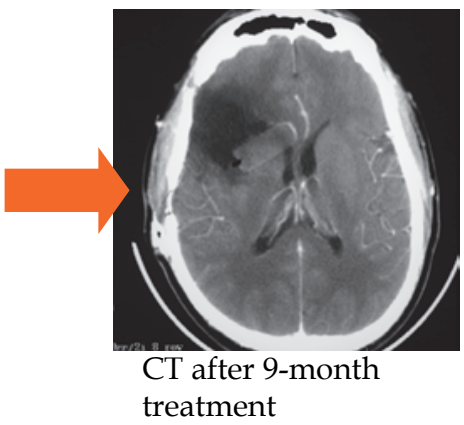

Fig. 9. The sketch of intratumoral brachytherapy 
The isotopes emited high-energetic particles to damage the ultra micro-structure of DNA in MG cells. Simultaneously, hyperplasia of vascular endotheliocytes was induced, reducing blood supply to the tumor.

According to the radiometric determination from the water and wax model, brachytherapy produced a 3- to 5-fold larger absorption than routine extracranial irradiation of 10-20 cGy/h. These results are in accordance with Gutin's report. To measure the radioactivity absorbed in the remnant tumor, we used an radioactivity detector (NE Company UK Ionex 2500/3) and a finger-shaped ionization chamber. Calculation using the formula Or $=51.2 \times \mathrm{C}$ $\sum \times($ niEi $\psi \mathrm{I}) \mathrm{cGy} / \mathrm{d}$ resulted in 30.4-91.3 cGy/h or 730-3190 cGy/d absorption by remnant tumor.

The extent of brain edema in normal brain tissue was lower than that after routine radiotherapy. Light and electron microscopy of brain tissue samples from a patient treated by intra-tumoral brachytherapy revealed that there was no tumor growth within 3 $\mathrm{cm}$ of the implanted radioactive source and that tumor cells $4 \mathrm{~cm}$ from the source were inactive.

This treatment offers several advantages over routine radiotherapy. First, the isotope was much closer to the residual tumor cells (Fig. 10). As a result, efficacy was improved; toxicity was reduced. Second, the isotope was sealed within the reservoir without leakage into the body. Third, survival time and quality of life improved in this treatment compared to the control group. The survival time increased with increasing radioactive dose. Finally, according to tumor proliferation during treatment, when patients need additional treatment, the reservoir can be refilled with the radioactive isotope through the subcutaneous valve.

\section{Typical case:}

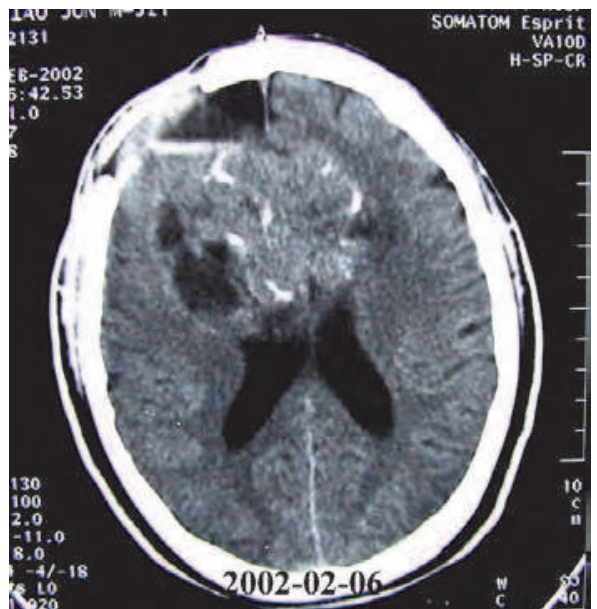

Postoperative CT scan before treatment

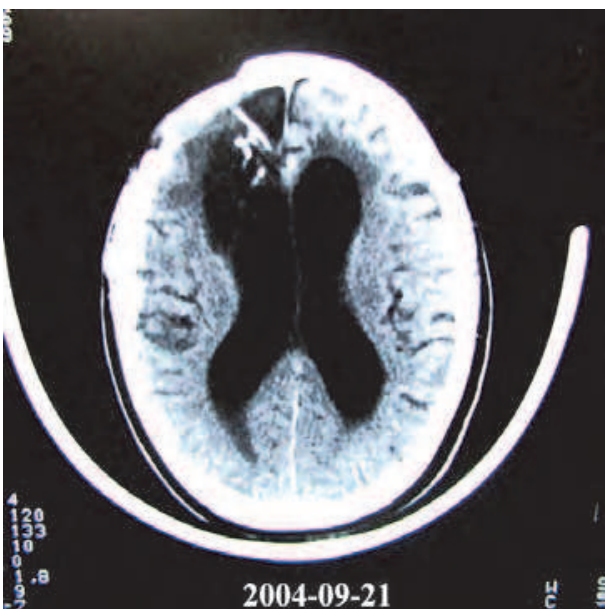

CT after 2-year treatment. The patient is still alive.

Fig. 10. The male patient was 57 years old with recurrent glioblastoma multiform, treated with intra-tumoral brachytherapy and intratumorally interstitial chemotherapy. 


\section{Intratumoral interstitial brachytherapy}

Beginning in 2002, the authors performed interstitial brachytherapy in patients with tumors in central or functionally important locations. The Li Anmin I reservoir was implanted stereotactically (Fig. 11-A). $1.5 \mathrm{~mL}$ of $30 \mathrm{mCi}{ }^{131}$ I solution was injected into the tumor site postoperatively at a constant speed $(0.25 \mathrm{~mL} / \mathrm{h})$. Tumor cells were eliminated by shortdistance radiation during the regeneration of interstitial fluid (Figs. 11-B and 12).

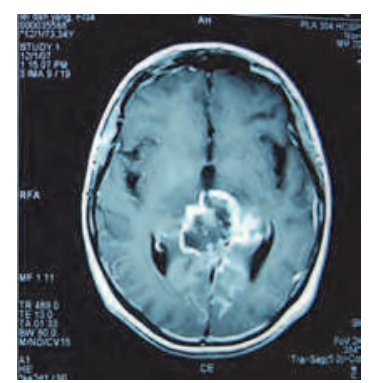

MRI befroe the second operation.

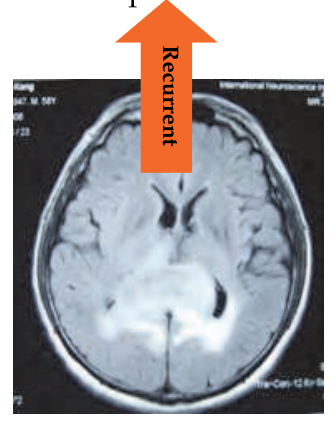

MRI before the first operation
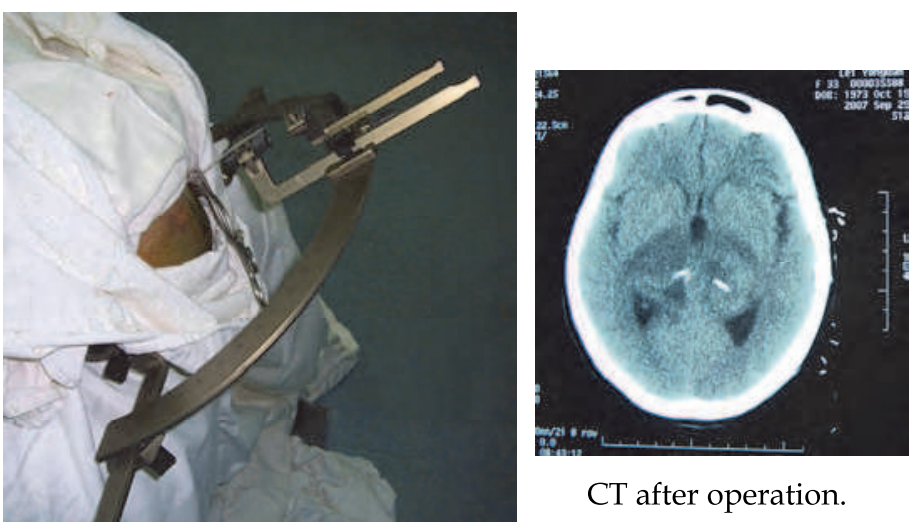

CT after operation.

Stereotactic operation

Fig. 11-A. The sketch of procedure of Intratumoral interstitial brachytherapy 


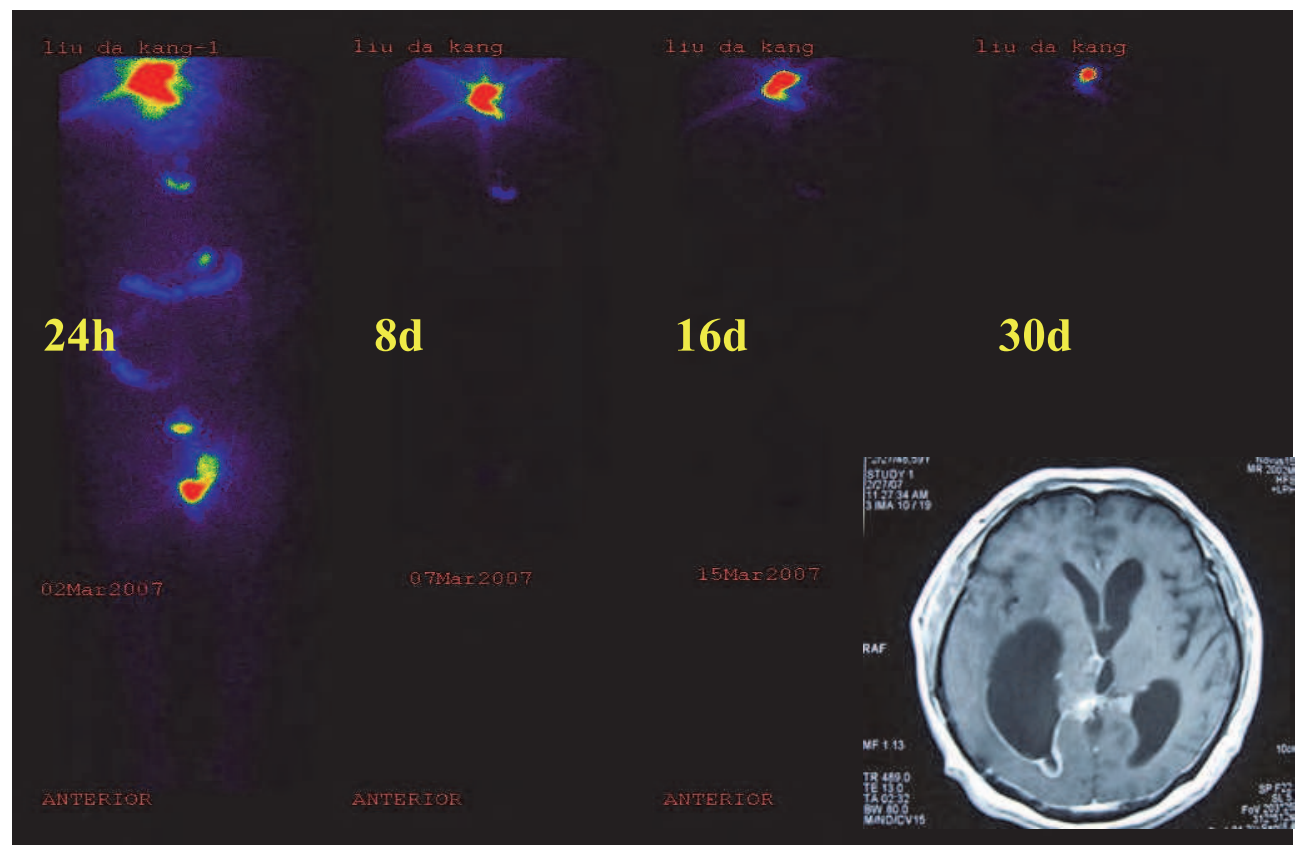

Fig. 11-B. CT and ECT at 24h, 8d, 16d and 30d after intratumoral interstitial brachytherapy.

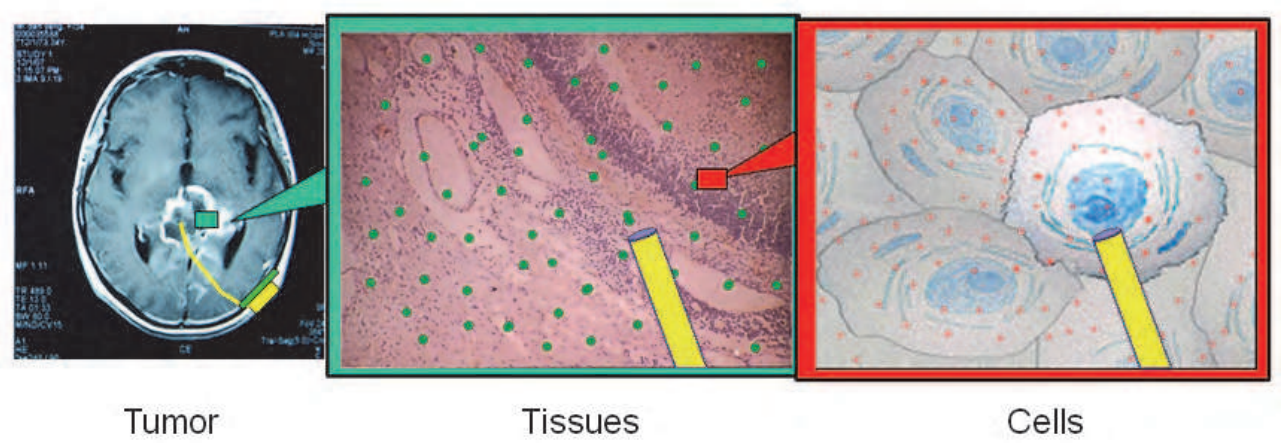

Fig. 12. The sketch of three structure levels of intratumoral interstitial brachytherapy for brain tumor.

This therapy involves three primary mechanisms (Fig. 13). First, a high-energy liquid radioactive source was placed at the interface of tumor and normal brain tissues, preventing the tumor from invading deep structures. Second, the liquid isotope flowed out of the reservoir into the interstitial fluid, irradiating tumor cells during the regeneration of the interstitial fluid. Finally, the liquid radioactive agents within the reservoir tube formed a radioactive column inside the tumor, subjecting it to continuous radiation for $>16 \mathrm{~d}$ ( 2 half lives of $\left.{ }^{131} \mathrm{I}\right)$. The ${ }^{131}$ I fluid can be refilled to prolong the radioactive exposure. 


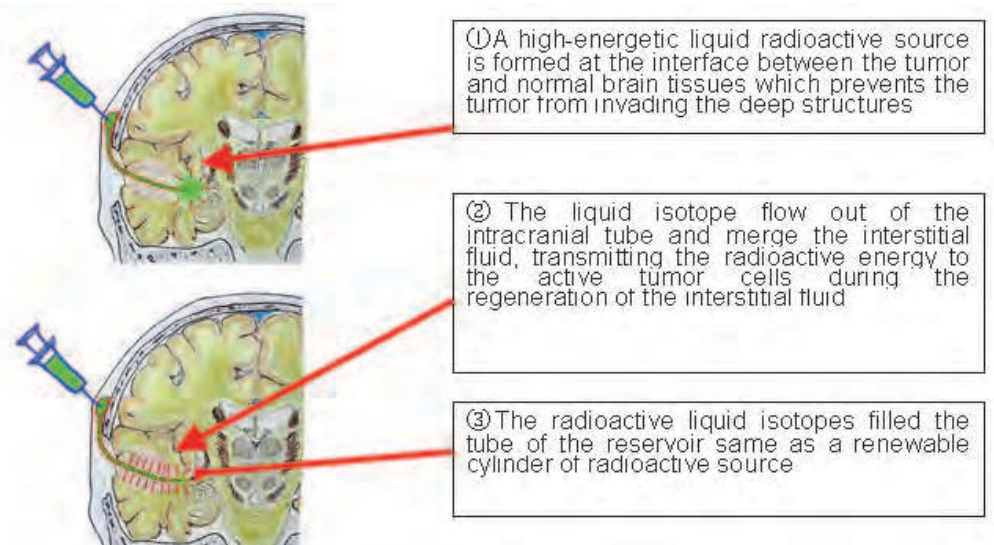

Fig. 13. The sketch of intratumoral interstitial brachytherapy

Based on long-term follow-up from Jan 2006 to Jul 2008, 33 patients who received the therapy had a prolonged survival time and a significantly improved quality of life (Fig. 14).

\section{Typical case:}
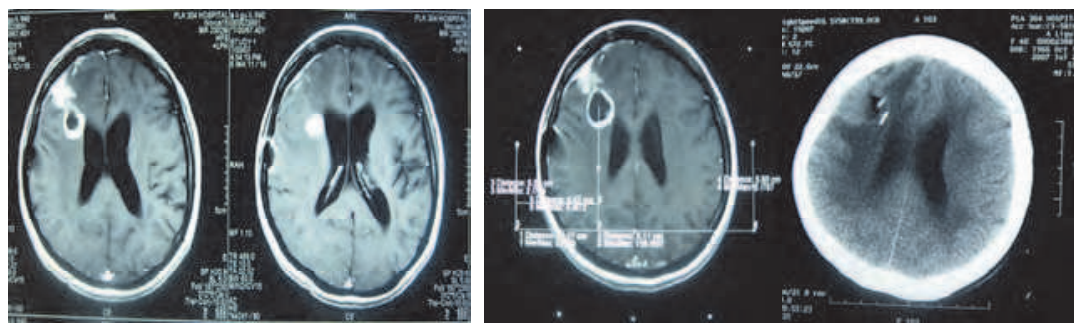

LiAnmin I reservoir was implanted

MRI of Recurrent glioma stereotactically.

Postoprational CT showed the position of intratumoral tube.

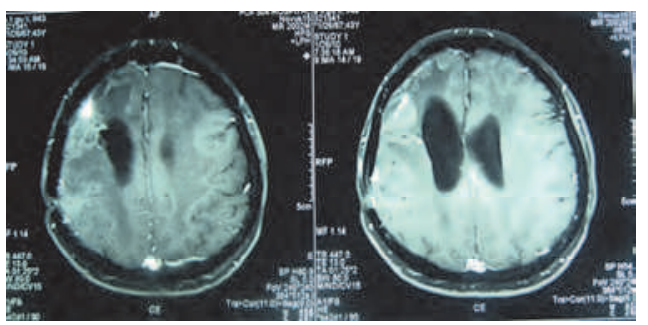

2.5 years after intratumoral interstitial brachytherapy

Fig. 14. Female, 42 years old, recurrent anaplastic astrocytoma

\section{Treatment:}

1. Intratumoral interstitial brachytherapy.

2. Selective/superselective interventional chemotherapy via cerebral artery 


\subsection{Complications and prevention}

Hypothyroidism is a common complication in patients receiving long-term, cumulative exposure to micro-doses of 131I, but could be prevented by iodine treatment prior to and during the exposure.

\section{Immunologically targeted radiotherapy via monoclonal antibodies (McAb) loaded with ${ }^{131}$ I}

Immunologically targeted radiotherapy was designed for targeted brachytherapy [11]. Due to the weak immunogenicity and heterogeneity of glioma cells, an anti-nucleus McAb loaded with 131I works better than an anti-membrane antibody. The chimeric McAb binds specifically to histones inside the dying tumor cells to destroy the adjacent tumor cells with high-dose local irradiation (Fig. 15).

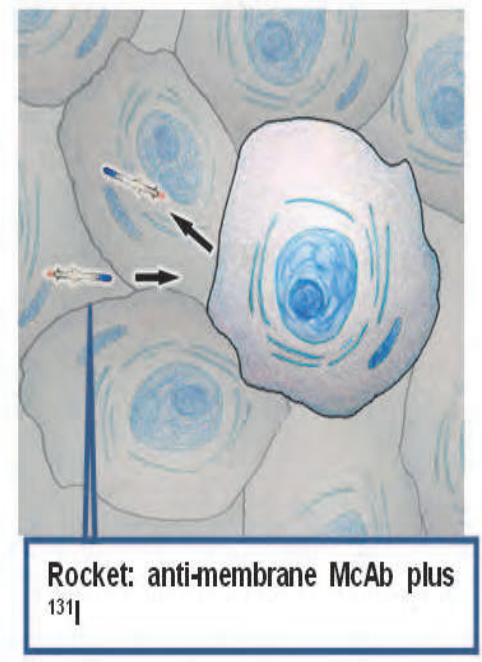

Illustration of Immunologically targeted radiotherapy via anti-membrane McAb the anti-membrane antibody couldn't recognize the antigen on membrane due to the weak immunogenicity and heterogenicity

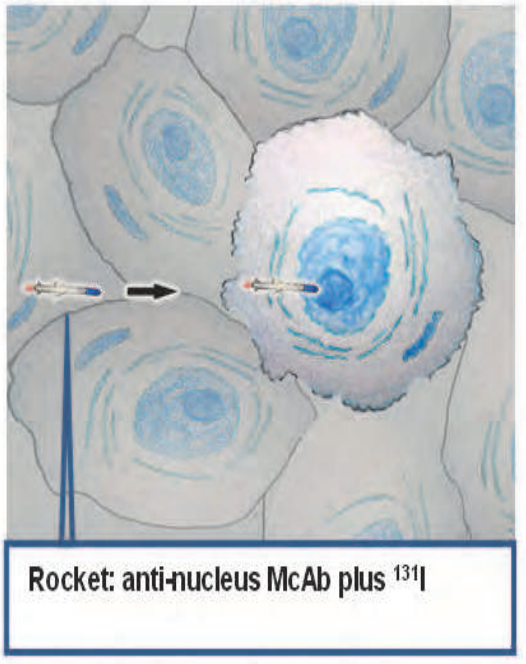

Illustration of Immunologically targeted radiotherapy via anti-nucleus McAb this chimeric McAb can specifically bind to the histone inside the necrotising tumor cells to perform high dose local irradiation

Fig. 15. Sketch of Comparison between Immunologically Targeted Radiotherapy via antimembrane and anti-nucleus McAb loaded ${ }^{131}$ I in glioma

In collaboration with Epstein at the Department of Pathology, University of Southern California, the authors completed a phase II clinical trial in $56 \mathrm{MG}$ patients in China. Of the 56 patients, $37.5 \%$ showed marked improvement and $42.8 \%$ showed mild improvement. The 1-year survival rate was $92.8 \%$.

The recommended intrathecal administration resulted in accumulation of radioactive isotopes in the subarachnoid space and cerebral cistern rather than in the tumor tissue (Fig. 16). Additionally, intrathecal administration induced adverse effects on thyroid and bone marrow. 
By contrast, when drugs were administered to the tumor via the Li Anmin I reservoir, the adverse effects on the thyroid and bone marrow were reduced (Fig. 17).

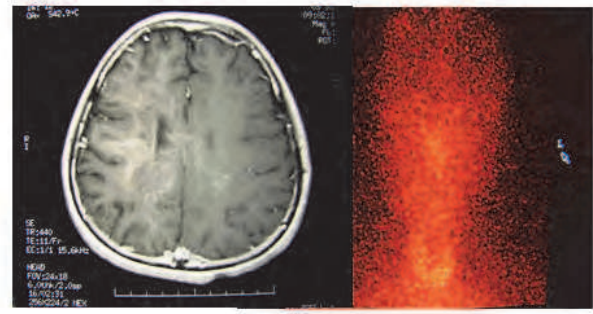

48 hours after intrathecal administration, ECT showed that radioactive isotopes mainly in the thyroid and cerebral cistern, not in the tumor

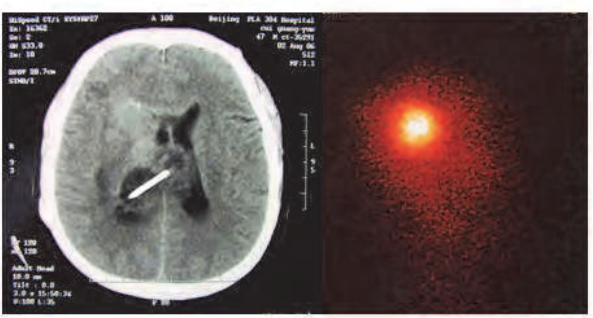

48 hours after local administration, ECT showed that radioactive isotopes mainly in the tumor, not in the thyroid and cerebral cistern

Fig. 16. ECT images of 2 methods of treatment

In May 2004, the China Cooperation Team Conference of Immune Targeted Radiotherapy was held in Shanghai. The authors proposed the local administration with LiAnmin I reservoir, which got extensive affirmation and widely accepted as the general method of immune targeted radiotherapy for MG in China.

\section{Typical case:}

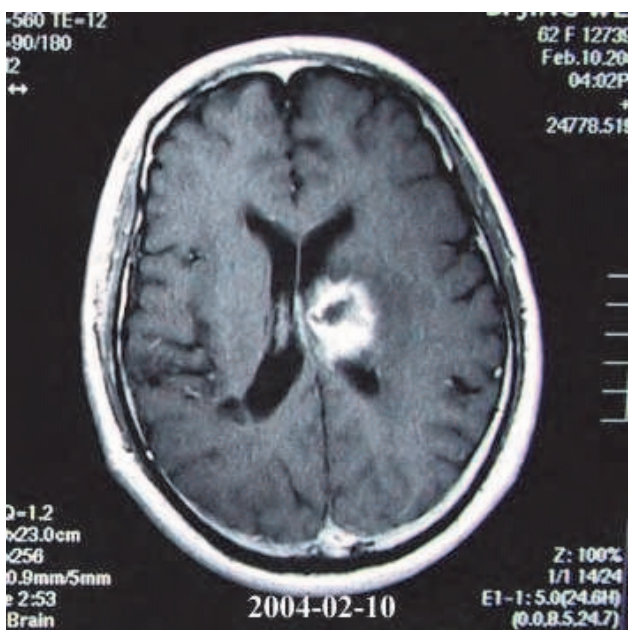

Before treatment

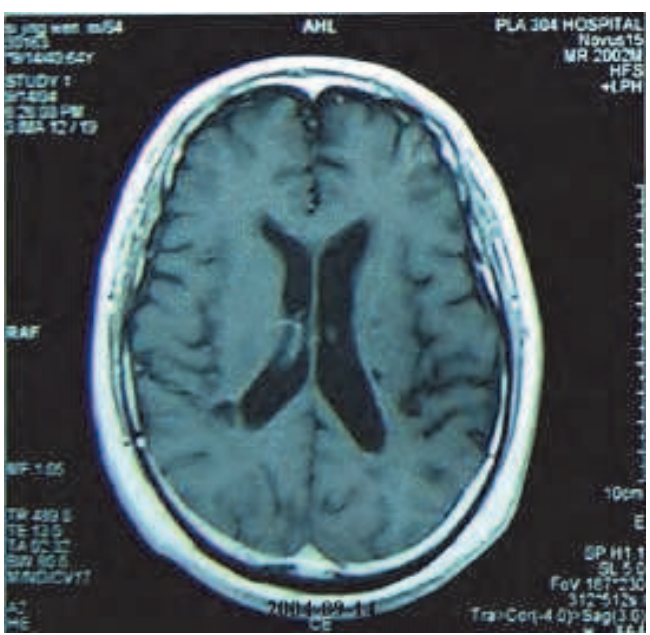

7 years after treatment

Fig. 17. Male, 62 years old, GBM

\section{Treatment:}

1. Immunologically targeted radiotherapy via McAb loaded 131I

2. Selective interventional chemotherapy via cerebral artery 
Following positive reception at the China Cooperation Team Conference of Immune Targeted Radiotherapy (Shanghai, May 2004), local administration of anti-nucleus McAb loaded with ${ }^{131} \mathrm{I}$ via the $\mathrm{Li}$ Anmin I reservoir gained wide acceptance, and has become the golden standard of immune targeted radiotherapy for MG in China.

\section{Peritumoral brachytherapy for MG in the brain stem/spinal cord}

MG accounts for $59 \%$ of tumors in the brain stem and approximately $15 \%$ of the tumors in the spinal cord. Their survival rate is not correlated to the extent of surgical resection, but to the aggressiveness and postoperative proliferation of the residual tumor. Because of the infiltrative growth of the tumor, surgical resection has the risk of damaging the brain stem and spinal cord and threatening the quality of life. Conventional radiotherapy only inhibits tumor growth for $\sim 3$ months and does not affect the recurrent tumor.

Between Sept 2005 and Dec 2008, 15 patients were treated with peritumoral brachytherapy. In a follow-up of 1-3 yr, tumor control was seen in all cases. In 4 cases, the tumor disappeared. Shrinkage of the tumor was seen in 7 cases and maintained in 6 cases for 6-12 months. In the remaining 4 cases, tumor size remained stable for 1 year.

\subsection{Methods}

The treatment consisted of surgery and postoperative brachytherapy. For brain stem MG, the occipital squama and posterior arch of the atlas were removed. In spinal cord MG, laminectomy was performed for decompression in the two adjacent normal vertebral plates. Biopsies were conducted as needed. The intra-tumoral sack of the reservoir (Li Anmin I reservoir) was implanted near the tumor (Fig. 18). After $7 \mathrm{~d}$, liquid $30 \mathrm{mCi}{ }^{125 I} /{ }^{131} \mathrm{I}$ was injected via the reservoir valve into the intra-tumoral sack. Radioactive isotope was administered every four months (2 half lives of $\left.{ }^{125} \mathrm{I}\right)$ or 16-21 days (2-3 half lives of $\left.{ }^{131} \mathrm{I}\right)$ for four doses in one cycle. Most of the 15 patients received three treatment cycles. Two patients with brain stem MG received two $30 \mathrm{mCi}{ }^{131}$ I treatments. MRI examination was performed at 4 months after therapy.

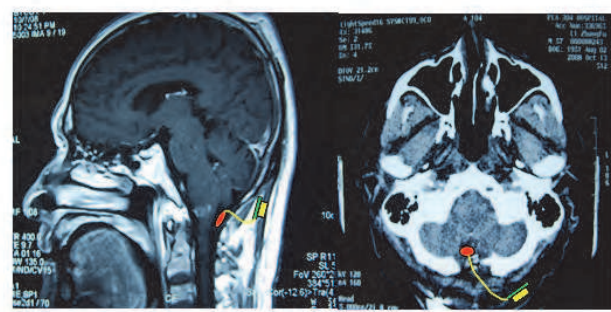

Illustration of peritumoral brachytherapy for brain stem glioma

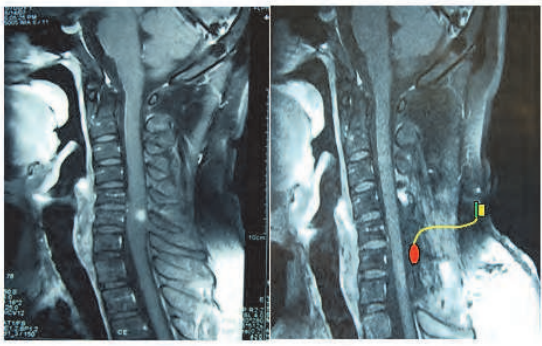

Illustration of peritumoral brachytherapy for spinal cord glioma

Fig. 18. The sketch of peritumoral brachytherapy for brain stem/spinal cord glioma

\subsection{Efficacy}

Brachytherapy has the advantages of localized high-absorption, long treatment cycles, and low radioactive injury to normal neural tissue, and therefore is suitable for patients with MG 
the brain stem or spinal cord [12,13]. The 15 patients receiving this therapy exhibited improved short-term and long-term survival. Two patients survived for $>3$ years. Posttreatment MRI revealed that all primary tumors were under control or in partial remission (Figs. 19 and 20).

\section{Typical case:}

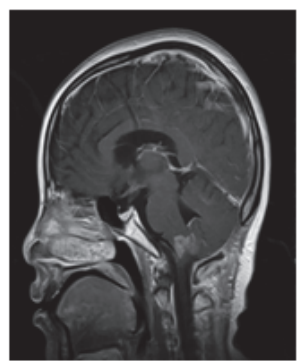

Before treatment

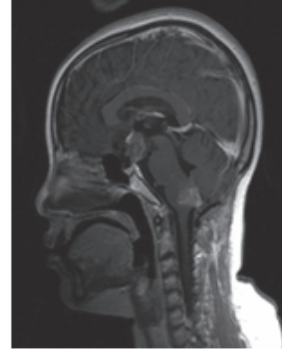

4 months after treatment

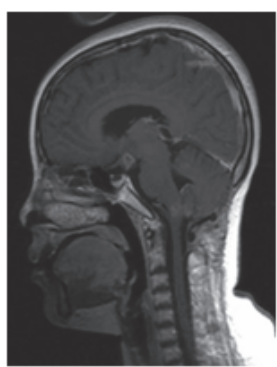

8 months after treatment

Fig. 19. Female, 11 years old, medulloblastoma

Treatment: peritumoral Brachytherapy for brain stem glioma

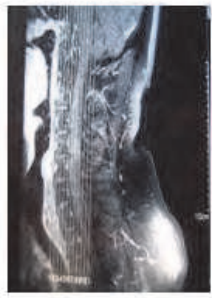

Before treatment

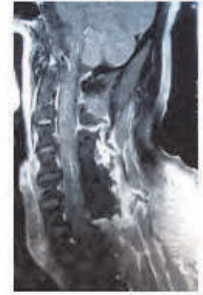

1 month after treatment

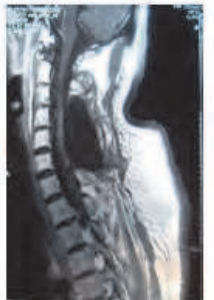

11 months after treatment

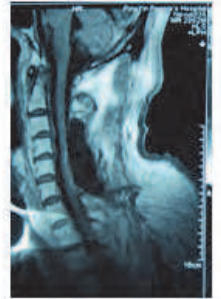

5 years after treatment

Fig. 20. Male, 46 years old, anaplastic astrocytoma in the cervical cord

Treatment: peritumoral brachytherapy for spinal cord glioma

\subsection{Clinical application of new regional tumor therapy}

Traditional treatments ignore the fact that MG is a localized tumor and target the entire body or the entire brain. Such treatments impair the immune and hemotopoeitic systems, and drastically reduce the quality of life. Based on pathogenesis, proliferation, pathological types, recurrence mode, and age at onset, MG is classified into six categories: primary glioma, recurrent glioma, cystic glioma, glioma in functional zones, low-grade glioma, and brain stem/spinal cord glioma. 
With the goal of improving the quality of life for MG patients, the authors developed seven new regional therapeutic methods. Long-term therapeutic plan was individualized for each patient.

Intra-tumoral brachytherapy and selective/super-selective interventional chemotherapy were commonly used in combination in our practice. A second common treatment combination included brachytherapy, intra-tumor interstitial chemotherapy, and selective/super-selective interventional chemotherapy via cerebral artery. (Table 2).

\begin{tabular}{|c|c|c|c|c|c|c|}
\hline & $\begin{array}{c}\text { primary } \\
\text { glioma }\end{array}$ & $\begin{array}{c}\text { recurrent } \\
\text { glioma }\end{array}$ & $\begin{array}{l}\text { cystic } \\
\text { glioma }\end{array}$ & $\begin{array}{l}\text { glioma in } \\
\text { functional } \\
\text { zones }\end{array}$ & $\begin{array}{l}\text { low- } \\
\text { grade } \\
\text { glioma }\end{array}$ & $\begin{array}{l}\text { Brainstem } \\
\text { /-spinal } \\
\text { cord } \\
\text { glioma }\end{array}$ \\
\hline $\begin{array}{l}\text { Intra-tumoral interstitial } \\
\text { chemotherapy }\end{array}$ & $\odot$ & $\odot$ & $\odot$ & & $\odot$ & \\
\hline $\begin{array}{l}\text { Selective/super-selective } \\
\text { interventional chemotherapy } \\
\text { via cerebral artery }\end{array}$ & $\odot$ & $\odot$ & $\odot$ & $\odot$ & $\odot$ & \\
\hline $\begin{array}{l}\text { Autologous peripheral blood } \\
\text { bone marrow stem cell } \\
\text { supported high-dose } \\
\text { chemotherapy }\end{array}$ & $\odot$ & $\odot$ & & & & \\
\hline Intratumoral brachytherapy & $\odot$ & $\odot$ & $\odot$ & & $\odot$ & \\
\hline $\begin{array}{l}\text { Immunologically targeted } \\
\text { radiotherapy via }{ }^{131} \text { I loaded } \\
\mathrm{McAb}\end{array}$ & & $\odot$ & & & & \\
\hline $\begin{array}{l}\text { Intratumoral interstitial } \\
\text { brachytherapy }\end{array}$ & & & & $\odot$ & & \\
\hline $\begin{array}{l}\text { Peritumoral brachytherapy for } \\
\text { brain stem/spinal cord glioma }\end{array}$ & & & & & & $\odot$ \\
\hline
\end{tabular}

Table 2. Clinical treatments of the six MG categories.

The overall 1-year, 2-year, and 3-year survival rate in our patients was $65.0 \%, 47 \%$, and $16.6 \%$, respectively. The tumor completely disappeared in $6.3 \%$ of the patients. This outcome is significantly better than previously reported (Table 3). 


\begin{tabular}{|c|c|c|c|c|c|c|c|}
\hline & country & Time & cases & Therapeutic regimen & $\begin{array}{l}\text { 1-year } \\
\text { survival } \\
\text { rate } \\
(\%)\end{array}$ & $\begin{array}{l}\text { 2-year } \\
\text { survival } \\
\text { rate } \\
(\%)\end{array}$ & $\begin{array}{l}\text { 3-year } \\
\text { survival } \\
\text { rate } \\
(\%)\end{array}$ \\
\hline Bloom & UK & 1966 & 141 & Surgery + Radiotherapy & 27 & 15 & 8 \\
\hline Fine & USA & 1993 & 3000 & $\begin{array}{l}\text { Surgery }+ \\
\text { Radio/chemotherapy }\end{array}$ & 53.2 & 25.0 & - \\
\hline Scott & USA & 1995 & 747 & $\begin{array}{l}\text { Surgery + } \\
\text { Radio/chemotherapy }\end{array}$ & 30 & 8 & 2.5 \\
\hline Davis & USA & 1999 & 146 & Surgery + Radiotherapy & 46 & 9.0 & 3.0 \\
\hline Laws & USA & 2004 & 565 & $\begin{array}{l}\text { Surgery + } \\
\text { Radio/chemotherapy }\end{array}$ & - & 34.5 & - \\
\hline $\begin{array}{l}\mathrm{Li} \\
\text { Anmin }\end{array}$ & $\mathrm{CHN}$ & 2008 & 379 & Local Therapy & 65 & 47 & 16.6 \\
\hline
\end{tabular}

Note: Above data were from following articles:

Table 3. Clinical outcome of glioma treatments.

[1] Fine HA, Dear KB, Loeffler JS, Black PM, Canellos GP. Meta-analysis of radiation therapy with and without adjuvant chemotherapy for malignant gliomas in adults. Cancer. 1993, 71(8):2585-97.

[2] Scott CB, Nelson JS, Farnan NC, Curran WJ Jr, Murray KJ, Fischbach AJ, Gaspar LE,Nelson DF.Central pathology review in clinical trials for patients with malignant glioma. A Report of Radiation Therapy Oncology Group 83-02. Cancer. 1995, 76(2):307-13.

[3] Chen P, Aldape K, Wiencke JK, Kelsey KT, Miike R, Davis RL, Liu J, Kesler-Diaz A,Takahashi M, Wrensch M. Ethnicity delineates different genetic pathways in malignant glioma. Cancer Res. 2001, 61(10):3949-54.

[4] Chang SM, Parney IF, Huang W, Anderson FA Jr, Asher AL, Bernstein M, Lillehei KO, Brem H, Berger MS, Laws ER; Glioma Outcomes Project Investigators. Patterns of care for adults with newly diagnosed malignant glioma. JAMA. 2005, 293(5):55764.

\section{Magnetic targeting chemotherapy against brain gliomas}

One of the major problems in chemotherapy for MG is the lack of permeation of chemotherapeutic drugs through the BBB and tumor cell membrane. These difficulties may be overcome by novel delivery methods. For example, we developed a magnetic targeting drug delivery system between 1995 and 2008 (Fig.21). We conducted a series of experiments 
to examine the distribution, efficacy, and potential toxicity of this system. Results are summarized below.

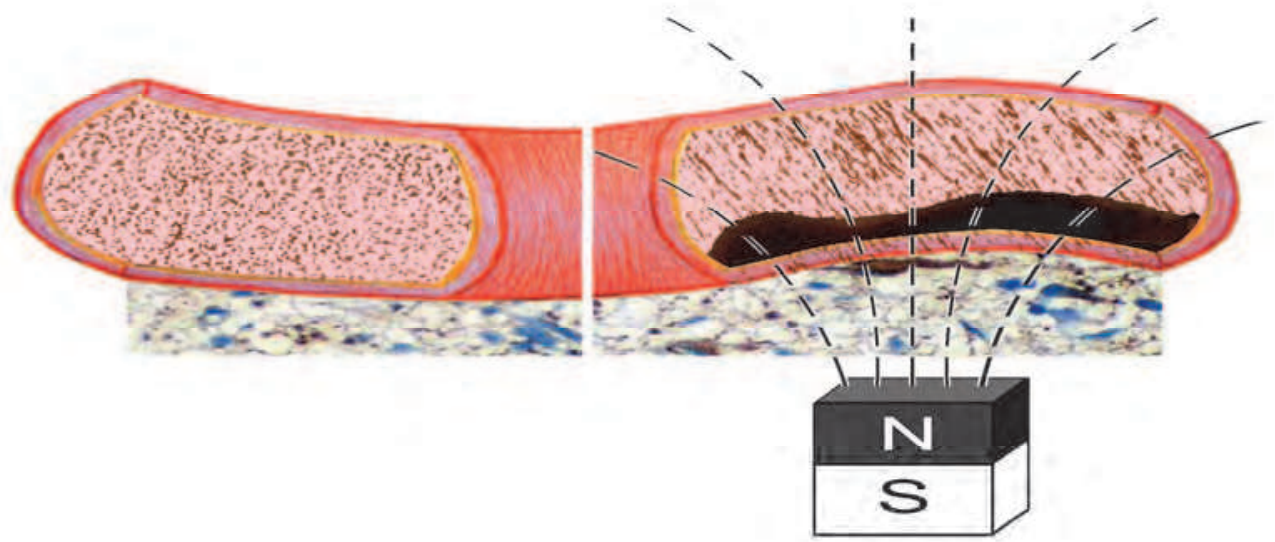

Fig. 21. The sketch of magnetic targeting delivery system

\section{Toxicity of magnetic drugs on liver, kidney, and bone marrow}

\subsection{Methods}

Sixty Kunming mice were randomly divided into three groups, and received different drugs in the presence or absence of an external magnetic field (Table 4). RBC, WBC, PLT, alamine aminotransferase (ALT), and blood urea nitrogen (BUN) were measured prior to and at 1, 7, 14,30 , and $90 \mathrm{~d}$ after the treatment.

\begin{tabular}{lll}
\hline Groups & Drug & External Magnetic Field \\
\hline Magnetic targeting & magnetic MTX drug & $0.5 T$, across head \\
MTX & MTX & Without \\
Control & saline & Without \\
\hline
\end{tabular}

Table 4. Toxicity profile.

\subsection{Results}

RBC, WBC, and PLT counts in the MTX group decreased significantly after the treatment, reached the lowest levels at $14 \mathrm{~d}$ post-injection and recovered after $90 \mathrm{~d}$. In the magnetic targeting group, the RBC count was lowest at $7 \mathrm{~d}$ post-injection and gradually recovered after $90 \mathrm{~d}$.

Remarkable difference was found among three groups, as shown in Fig. 22, demonstrating that magnetic targeting can reduce the toxicity of chemical drugs on bone marrow. Changes in ALT and BUN levels reflected the hepatic and renal injury. The magnetic targeting group had markedly lower ALT and BUN levels compared to the MTX group, indicating that magnetic targeting can reduce the side effects of chemotherapeutic drugs and protect the liver, kidneys, and bone marrow from systemic chemotherapy [14]. 

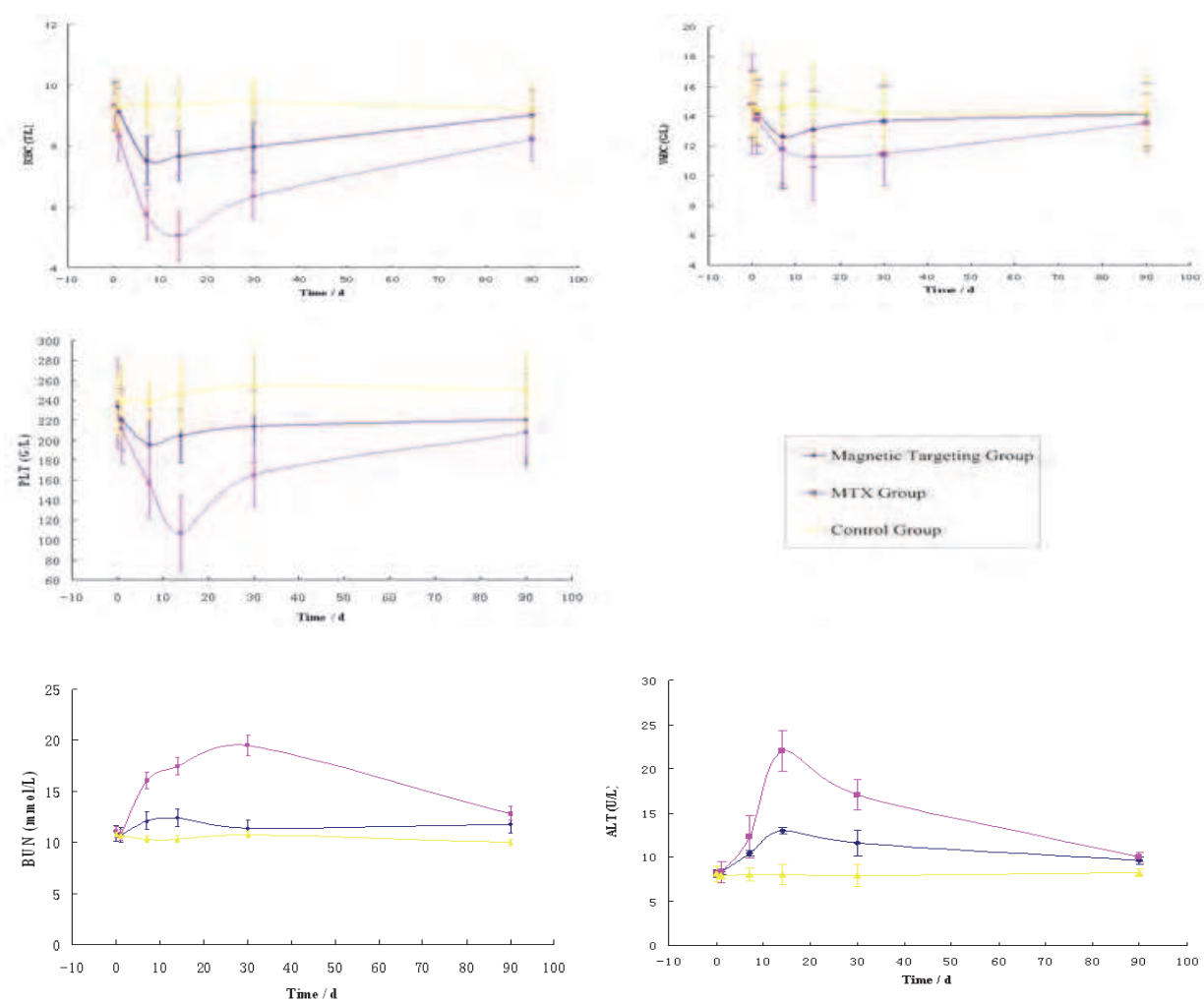

Fig. 22. Peripheral levels of RBC, WBC, PLT, ALT and BUN at pre-injection, and 1, 7, 14, 30 and $90 \mathrm{~d}$ after drug injection.

\section{Distribution of the magnetic drugs in the brain}

We investigated the distribution of magnetic drugs in the brain under magnetic drug targeting and explored magnetic targeting chemotherapy for malignant brain tumors.

\subsection{Methods}

Ninety SD rats were divided into three groups, and received different drugs in the presence or absence of an external magnetic field (Table 5). Ten rats from each group were randomly selected for sacrifice at 15 min intervals after drug injections. MTX levels in both sides of brain of each rat were measured.

\begin{tabular}{lll}
\hline Groups & Drug & External Magnetic Field \\
\hline Magnetic targeting & magnetic MTX drug & $0.5 T$, across head \\
Non-magnetic targeting & magnetic MTX drug & without \\
Control & MTX & $0.5 \mathrm{~T}$, across head \\
\hline
\end{tabular}

Table 5. Distribution of magnetic drugs in the brain. 


\subsection{Results}

MTX concentration in the brain was significantly higher in the magnetic targeting group. The difference between the three groups increased with time after injection.

\begin{tabular}{lccc}
\hline \multirow{2}{*}{ Group } & \multicolumn{3}{c}{ Drug content in hemispheres post-injection } \\
\cline { 2 - 4 } & $15 \mathrm{~min}$ & $30 \mathrm{~min}$ & $45 \mathrm{~min}$ \\
\hline Magnetic targeting & $0.28 \pm 0.03 \mathrm{a}$ & $0.38 \pm 0.04 \mathrm{a}$ & $0.56 \pm 0.02 \mathrm{a}$ \\
Non-magnetic targeting & $0.10 \pm 0.02$ & $0.14 \pm 0.01$ & $0.06 \pm 0.02$ \\
MTX & $0.13 \pm 0.12$ & $0.11 \pm 0.02$ & $0.07 \pm 0.05$ \\
\hline
\end{tabular}

Note: a: $P<0.01$ vs. other groups

Table 6. MTX concentration in the brain hemispheres.

\subsection{Conclusions}

Under magnetic targeting, magnetic drugs accumulated in the targeted area in the brain and local drug concentrations increased by 2- 9 folds.

\section{Drug delivery by Superparamagnetic Paclitaxel Nanoparticles (SPPNPs)}

\subsection{Preparation and characteristics of SPPNPs}

\subsubsection{Methods}

SPPNPs were synthesized with octadecyl-quaternized carboxymethyl chitosans and $\mathrm{Fe}_{3} \mathrm{O}_{4}$ ferrofluid, cholesterol, and paclitaxel at a weight ratio of 4:3:3:2 by reverse-phase evaporation. The diameters, magnetism, and drug release rates of the SPPNPs were examined with transmission electron microscope (TEM), a vibrating sample magnetometer (VSM), and high performance liquid chromatography (HPLC).

\subsubsection{Results}

TEM revealed an average diameter of $\sim 20 \mathrm{~nm}$ with a narrow size distribution. The VSM analysis indicated that the paclitaxel nanoparticles were superparamagnetic (Fig. 23). The drug release test showed sustained drug release for $>15$ days (Fig. 24).

\subsection{Cellular study}

\subsubsection{Methods}

We examined intracellular distribution of FITC-labeled SPPNPs in MG cell line C6 under a fluorescent microscope. Cytotoxicity and apoptosis-inducing capacity of SPPNPs were also examined using CCK-8 kit and flow cytometry, respectively.

\subsubsection{Results}

The nanoparticles were taken up by the glioma cells. Confocal microscopy showed that these nanoparticles are present in the cytoplasm. C6 Cells were incubated with magnetic paclitaxel nanoparticles containing 1-80 $\mathrm{nM}$ paclitaxel or free paclitaxel of the same concentrations for 6-24 h. Both free placlitaxel and magnetic paclitaxel nanoparticles inhibited the proliferation of C6 cells in a dose and time-dependent manner. Cytotoxicity was comparable between free paclitaxel and paclitaxel released from the magnetic nanoparticles (Fig. 25). 


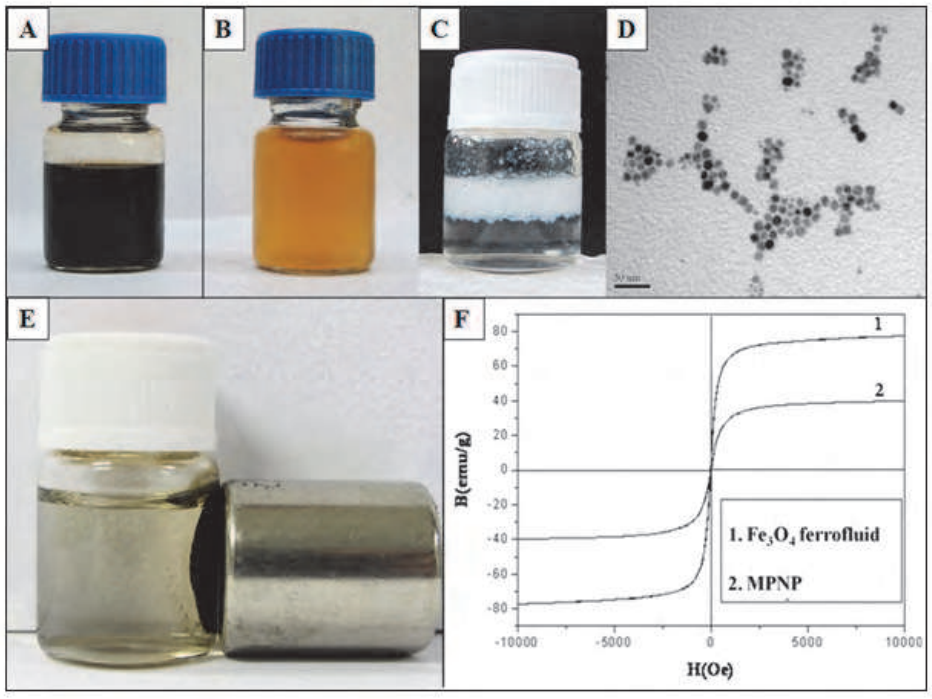

(Magnetic paclitaxel nanoparticles inhibit glioma growth and improve the survival of rats bearing glioma xenografts. Anticancer Research, 2010; 30(6): 2217-2223.)

Fig. 23. The aqueous solution of the magnetic paclitaxel nanoparticles at a concentration of 1 $\mathrm{mg} / \mathrm{ml}(\mathrm{A})$ and $0.02 \mathrm{mg} / \mathrm{ml}$ (B) (calculated by the paclitaxel content). The same concentration of free paclitaxel $(1 \mathrm{mg} / \mathrm{ml})$ was insoluble in water $(C)$. Under transmission electronic microscope, the magnetic paclitaxel nanoparticles showed a uniform size of $20 \mathrm{~nm}$ in diameter (D). After an external magnet was placed, the nanoparticles were attracted to the container wall (E). Vibrating sample magnetometry showed that these nanoparticles were superparamagnetic $(\mathrm{F})$.

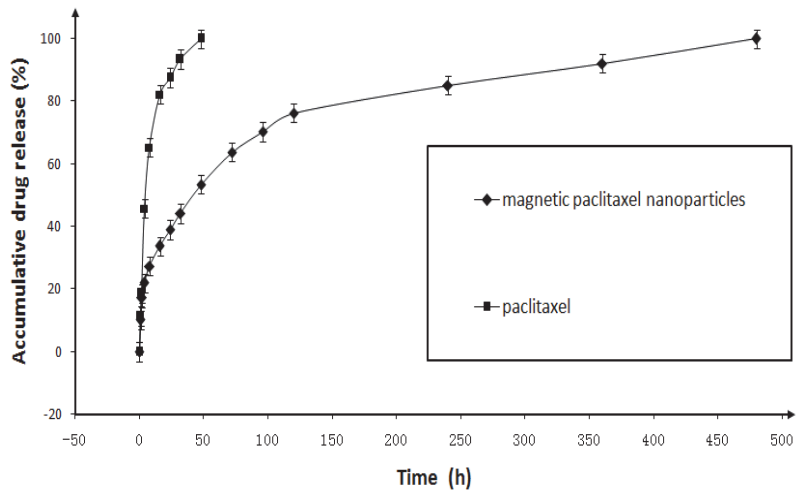

Fig. 24. In vitro paclitaxel release of free paclitaxel and the magnetic paclitaxel nanoparticles $\left(\mathrm{pH} 7.4\right.$ at $\left.37^{\circ} \mathrm{C}\right)$. The results are shown as mean \pm S.D.. The experiments were conducted three times independently. (Magnetic paclitaxel nanoparticles inhibit glioma growth and improve the survival of rats bearing glioma xenografts. Anticancer Research, 2010; 30(6): 2217-2223.) 


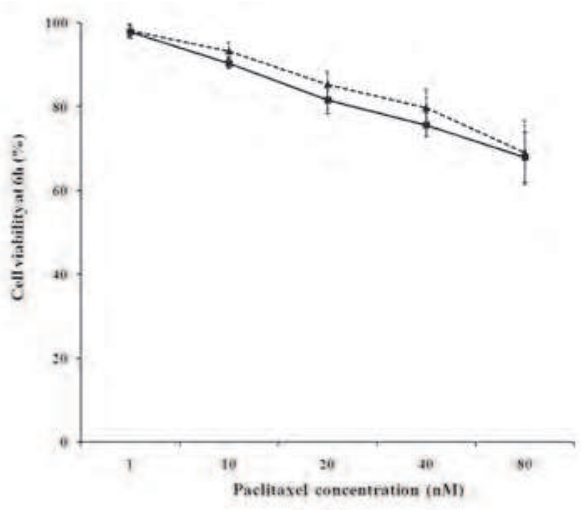

(A)

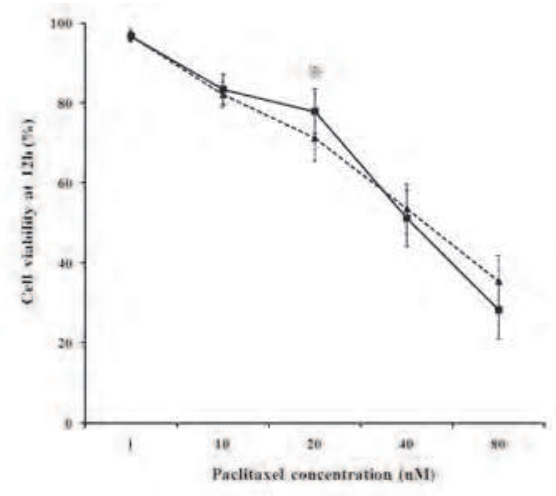

(B)

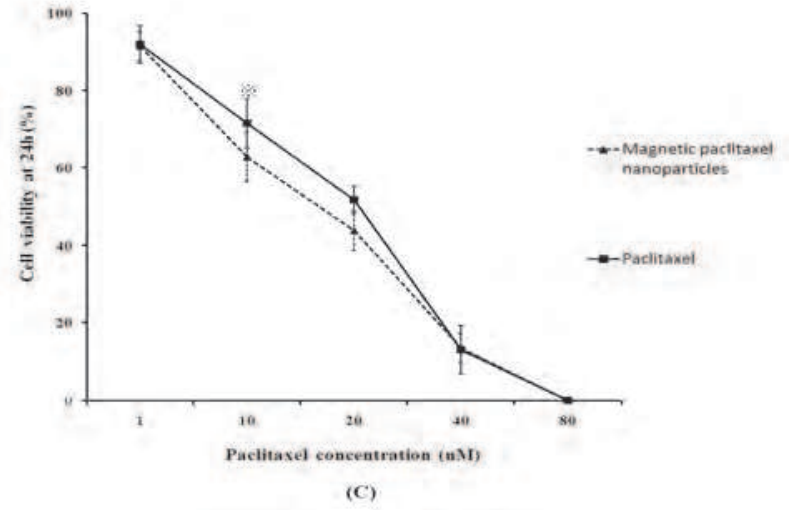

Fig. 25. The in vitro cytotoxicity of the magnetic paclitaxel nanoparticles and free paclitaxel against $\mathrm{C} 6$ cells at $6 \mathrm{~h}(\mathrm{~A}), 12 \mathrm{~h}(\mathrm{~B})$ and $24 \mathrm{~h}(\mathrm{C})$ post drug treatment. The cytotoxicity was determined by CCK-8 assays. The results are shown as mean \pm S.D.. The experiments were conducted three times independently. ${ }^{*}$ indicates $\mathrm{P}<0.05$. (Magnetic paclitaxel nanoparticles inhibit glioma growth and improve the survival of rats bearing glioma xenografts. Anticancer Research, 2010; 30(6): 2217-2223.)

\subsection{Animal experiments}

\subsubsection{Drug concentration in rat brains after magnetic targeting}

Male Wistar rats were randomly assigned into three groups, and received SPPNPs or PTX in the presence or absence of an external magnetic field (Table 7).

\begin{tabular}{lll}
\hline Groups & Drug & External Magnetic Field \\
\hline Magnetic targeting & SPPNP $(2.5 \mathrm{~mL} / \mathrm{kg})$ & $0.5 \mathrm{~T}$, across head \\
Non-magnetic targeting & SPPNP $(2.5 \mathrm{~mL} / \mathrm{kg})$ & without \\
Control & PTX $(1.0 \mathrm{mg} / \mathrm{mL})$ & without \\
\hline
\end{tabular}

Table 7. Treatment conditions in rat experiments. 
The brain tissues were harvested at $1,4,8$, and $16 \mathrm{~h}$ post-injection. PTX concentration was measured by HPLC.

\subsubsection{Results}

After intravenous injection of SPPNP, the PTX concentration in the non-magnetic targeting group was significantly lower compared to the magnetic targeting group, but markedly higher than that in control group (Fig. 26).

\subsubsection{Inhibition of glioma cells in tumor-bearing rats after SPPNP injection and magnetic targeting}

\subsubsection{Methods}

C6 cells were implanted into the rat brain stereotactically. After emergence of brain tumor symptoms, rats were divided into three groups. They were treated as shown in the following Table 7.

\subsubsection{Results}

The effect of free paclitaxel or the SPPNPs on the survival of rats bearing C6 glioma was depicted in Fig. 5. We found that the rats that received free paclitaxel at $10 \mathrm{mg} / \mathrm{kg}$ had a median survival of $12 \mathrm{~d}$ and a mean survival of $13.6 \mathrm{~d}$ (Tab. 2). The rats that received the magnetic paclitaxel nanoparticles and magnetic targeting had a median survival of $27 \mathrm{~d}$ and a mean survival of $27.4 \mathrm{~d}$ with the longest survival at $34 \mathrm{~d}$, whose survival time increased for 1.5 times compared to those who received free paclitaxel (Fig. 27).

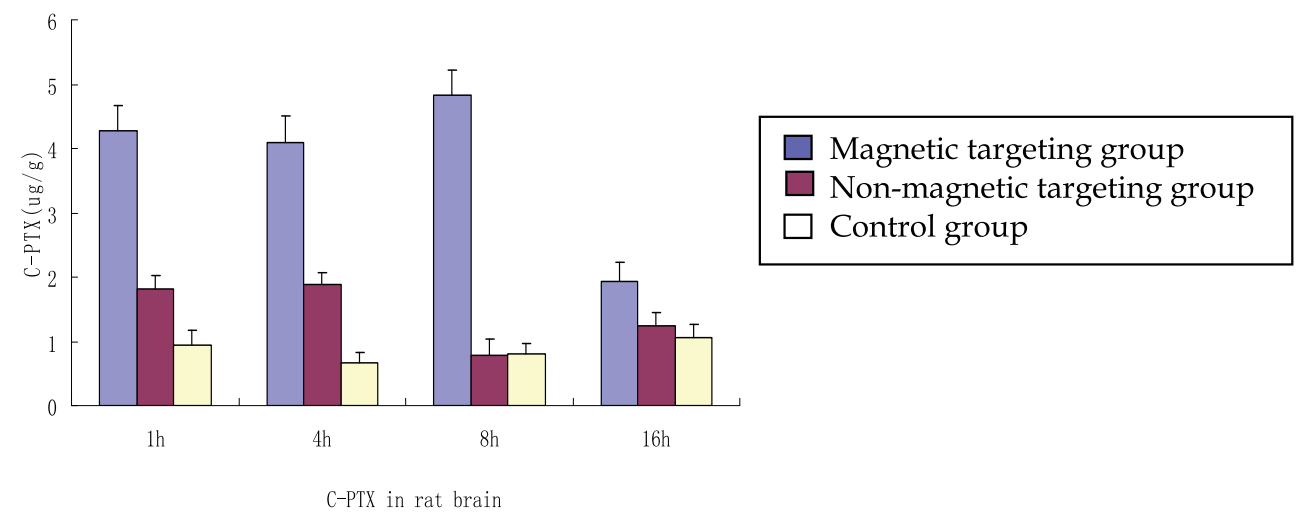

Fig. 26. Drug Concentration in Rat Brain in 3 Groups. 


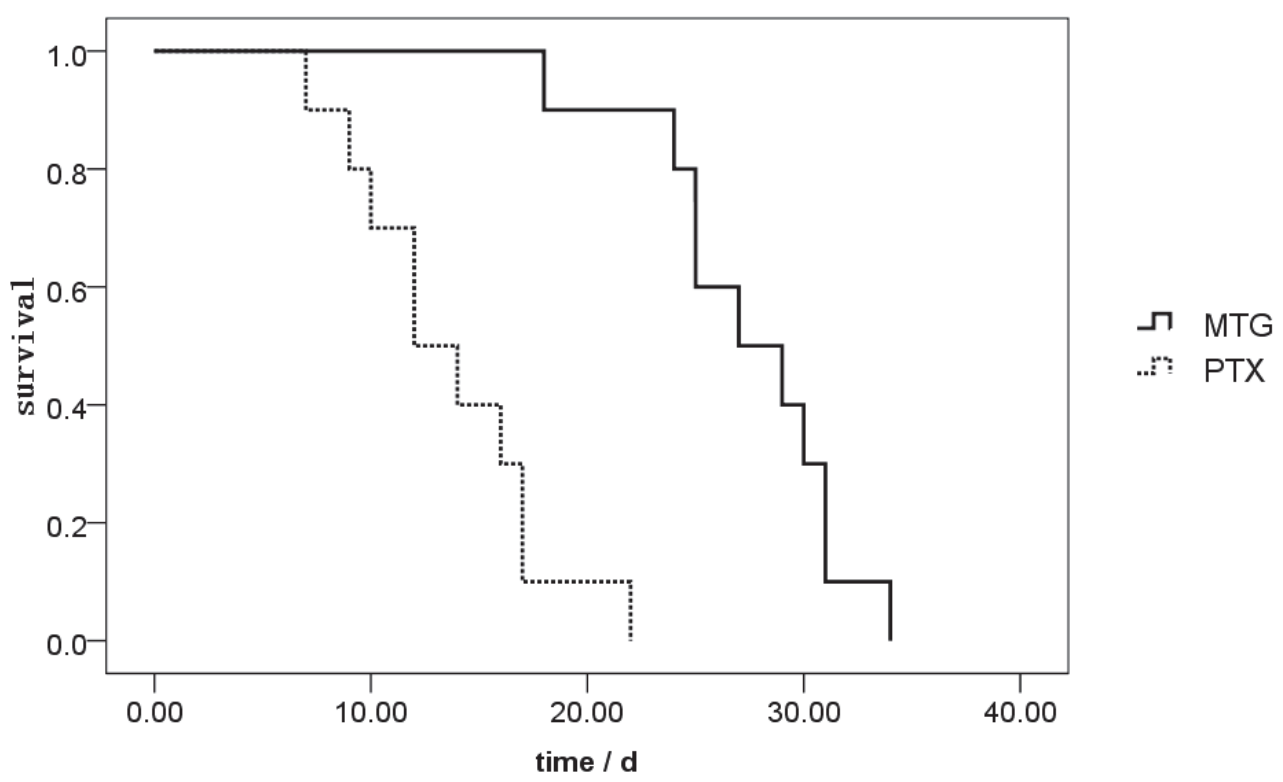

Fig. 27. Kaplan-Meier survival plots for C6 glioma-bearing rats given magnetic paclitaxel nanoparticles or free paclitaxel with or without magnetic targeting. MTG: magnetic targeting group, injection of magnetic paclitaxel nanoparticles combined with $0.5 \mathrm{~T}$ magnetic field across the head; PTX: commercial paclitaxel was administered. Significantly prolonged survival was found in the MTG. (Magnetic paclitaxel nanoparticles inhibit glioma growth and improve the survival of rats bearing glioma xenografts. Anticancer Research, 2010; 30(6): 22172223.) 


\section{Conclusion}

SPPNPs are safe and stable vectors to release chemotherapeutic drugs [15]. The small size allows SPPNPs to enter tumor cells. In the presence of an external magnetic field, SPPNPs can accumulate in magnetic targeted area [16,17]. This treatment inhibited tumor growth and prolonged the survival of glioma-bearing rats.

\subsection{Possible mechanisms of magnetic targeting therapy against MG}

\section{Increase localized drug concentration}

In the presence of an external magnetic field, magnetic chemotherapeutic drugs move within capillaries in the targeted areas of the brain and tumor. This increases the local drug concentration dramatically both around the tumor region and in the blood vessels of magnetic field [18]. Our results showed that magnetic targeting could increase the local drug concentration by $2-15$ folds.

\section{Slow release of loaded drugs}

In the magnetic targeted area, the biodegradable capsule of magnetic drugs constantly degrades, slowly releasing the drugs into the vasculature or interstitial space of tumors or inside the tumor cells. This slow-release produces a sustained inhibition of the tumor cells.

\section{Thrombosis by magnetic particles}

Neoplastic deformation of tumor vasculature and ferrofluid in the magnetic field may facilitate the formation of micro-thrombi in the tumor capillary vessel and microvessel, and decrease the blood supply to the tumor [19].

\section{Improve the penetration across biological membrane}

The penetration of drugs across BBB depends on the local concentration gradient across the brain endotheliocytes. Magnetic targeting increases the drug content in the interstitial fluid of tumor. In addition to this concentration gradient, the strong magnetic field promotes the movement of the magnetic drug into the tumor from the capillary vessels and microvessels. Permeability and endocytosis permit the magnetic particles and chemotherapeutic drugs to enter the tumor cells [20].

\section{Magnetic-chemotherapeutic effects of magnetic particles}

The magnetic particles and external magnetic field may have synergistic action. In traditional Chinese medicine, magnetite has been used to generate magnetic field in tumor patients. In magnetic targeting therapy, the encapsulated ferrofluid can generate the magnetic-chemotherapeutic antineoplastic effects [21].

\section{References}

[1] Wen PY and Kesari S: Malignant gliomas in adults. N Engl J Med 2008, 359: 492-507. 2008, 31;359(5):492-507.

[2] Gurney JG, Kadan-Lottick N: Brain and other central nervous system tumors: rates, trends, and epidemiology. Curr Opin Oncol 13:160-166, 2001, 13(3):160-6.

[3] Mamelak AN. Locoregional therapies for glioma. Oncology (Williston Park). 2005, 19(14):1803-10.

[4] Boiardi A, Silvani A, Eoli M, Lamperti E, Salmaggi A, Gaviani P, Fiumani A,Botturi A, Falcone C, Solari A, Filippini G, Di Meco F, Broggi G. Treatment of recurrent glioblastoma: can local delivery of mitoxantrone improve survival? J Neurooncol. 2008, 88(1):105-13. 
[5] Rhines LD, Sampath P, DiMeco F, Lawson HC, Tyler BM, Hanes J, Olivi A, Brem H. Local immunotherapy with interleukin-2 delivered from biodegradable polymer microspheres combined with interstitial chemotherapy: a novel treatment for experimental malignant glioma. Neurosurgery. 2003, 52(4):872-9.

[6] Engelhard $\mathrm{HH}$. The role of interstitial BCNU chemotherapy in the treatment of malignant glioma. Surg Neurol. 2000, 53(5):458-64.

[7] Boiardi A, Salmaggi A, Pozzi A, Broggi G, Silvani A. Interstitial chemotherapy with mitoxantrone in recurrent malignant glioma: preliminary data. J Neurooncol. 1996, 27(2):157-62.

[8] Sato M, Iwatsuki K, Akiyama C, Masana Y, Yoshimine T, Hayakawa T. Use of Ommaya CSF reservoir for refractory chronic subdural hematoma. No Shinkei Geka. 1999, 27(4):323-8.

[9] Jimbo Y, Uzuka T, Fujii Y. A case of cerebrospinal fluid hypovolemia caused by Ommaya reservoir successfully treated by epidural blood patch. No Shinkei Geka. 2008, 36(7):639-43.

[10] Drabko K, Wiśniewska-Slusarz H, Wójcik B, Choma M, Zaucha-Prazmo A, Kowalczyk JR. Megachemotherapy followed by autologous haematopoietic stem cell rescue in children with high risk CNS tumours. Med Wieku Rozwoj. 2005, 9(3 Pt 2):439-47.

[11] Kato Y, Vaidyanathan G, Kaneko MK, Mishima K, Srivastava N, Chandramohan V, Pegram C, Keir ST, Kuan CT, Bigner DD, Zalutsky MR. Evaluation of antipodoplanin rat monoclonal antibody NZ-1 for targeting malignant gliomas. Nucl Med Biol. 2010, 37(7):785-94.

[12] Julow J, Viola A, Major T, Valálik I, Sági S, Mangel L, Kovács BR, Repa I, Bajzik, G, Zoltán TN, Németh G.. Iodine-125 brachytherapy of brain stem tumors Strahlenther Onkol. 2004, 180(7):449-54.

[13] Chuba PJ, Zamarano L, Hamre M, Bhambhani K, Canady A, Guys MB, Matter A, Portillo G, Chung-bin S, Fontanesi J. Permanent I-125 brain stem implants in children. Childs Nerv Syst. 1998, 14(10):570-7.

[14] Alexiou C, Jurgons R, Schmid RJ, Bergemann C, Henke J, Erhardt W, Huenges E, Parak F. Magnetic drug targeting--biodistribution of the magnetic carrier and the chemotherapeutic agent mitoxantrone after locoregional cancer treatment. J Drug Target. 2003, 11(3):139-49.

[15] McBain SC, Yiu HH, Dobson J. Magnetic nanoparticles for gene and drug delivery. Int J Nanomedicine. 2008;3(2):169-80.

[16] Sakamoto J, Annapragada A, Decuzzi P, Ferrari M. Antibiological barrier nanovector technology for cancer applications. Expert Opin Drug Deliv. 2007, 4(4):359-69.

[17] Laquintana V, Trapani A, Denora N, Wang F, Gallo JM, Trapani G: New strategies to deliver anticancer drugs to brain tumors. Expert Opin Drug Deliv. 2009, 6(10):101732.

[18] Pulfer SK, Ciccotto SL, Gallo JM: Distribution of small magnetic particles in brain tumor-bearing rats. J Neurooncol. 1999, 41(2):99-105.

[19] Alexiou C, Jurgons R, Seliger C, Brunke O, Iro H, Odenbach S. Delivery of superparamagnetic nanoparticles for local chemotherapy after intraarterial infusion and magnetic drug targeting. Anticancer Res. 2007, 27(4A):2019-2022. 
[20] Hillaireau H, Couvreur P. Nanocarriers' entry into the cell: relevance to drug delivery. Cell Mol Life Sci. 2009, 66(17):2873-2896.

[21] Chertok B, David AE, Huang Y, Yang VC. Glioma selectivity of magnetically targeted nanoparticles: a role of abnormal tumor hydrodynamics. J Control Release. 2007, 122(3):315-323. 


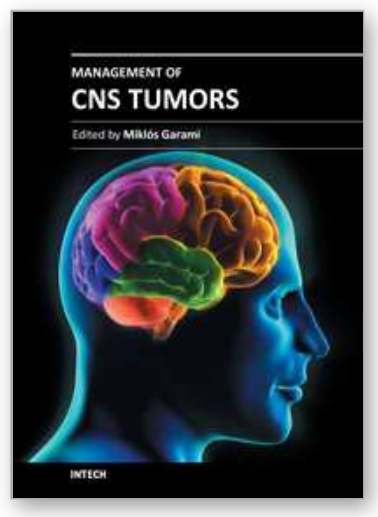

\author{
Management of CNS Tumors \\ Edited by Dr. Miklos Garami
}

ISBN 978-953-307-646-1

Hard cover, 464 pages

Publisher InTech

Published online 22, September, 2011

Published in print edition September, 2011

Management of CNS Tumors is a selected review of Central Nervous System (CNS) tumors with particular emphasis on pathological classification and complex treatment algorithms for each common tumor type. Additional detailed information is provided on selected CNS tumor associated disorders.

\title{
How to reference
}

In order to correctly reference this scholarly work, feel free to copy and paste the following:

Li Anmin, Fu Xiangping, Zhao Ming, Zhang Zhiwen, Yi Linhua, Xue Jinghui and Zhang Yipeng (2011). Regional Chemotherapy and Brachytherapy for Malignant Glioma - Clinical Experience and Serial Experiments, Management of CNS Tumors, Dr. Miklos Garami (Ed.), ISBN: 978-953-307-646-1, InTech, Available from: http://www.intechopen.com/books/management-of-cns-tumors/regional-chemotherapy-andbrachytherapy-for-malignant-glioma-clinical-experience-and-serial-experime

\section{INTECH}

open science | open minds

\author{
InTech Europe \\ University Campus STeP Ri \\ Slavka Krautzeka 83/A \\ 51000 Rijeka, Croatia \\ Phone: +385 (51) 770447 \\ Fax: +385 (51) 686166 \\ www.intechopen.com
}

\author{
InTech China \\ Unit 405, Office Block, Hotel Equatorial Shanghai \\ No.65, Yan An Road (West), Shanghai, 200040, China \\ 中国上海市延安西路 65 号上海国际贵都大饭店办公楼 405 单元 \\ Phone: +86-21-62489820 \\ Fax: +86-21-62489821
}


(C) 2011 The Author(s). Licensee IntechOpen. This chapter is distributed under the terms of the Creative Commons Attribution-NonCommercialShareAlike-3.0 License, which permits use, distribution and reproduction for non-commercial purposes, provided the original is properly cited and derivative works building on this content are distributed under the same license. 